\title{
Archives 6855
}
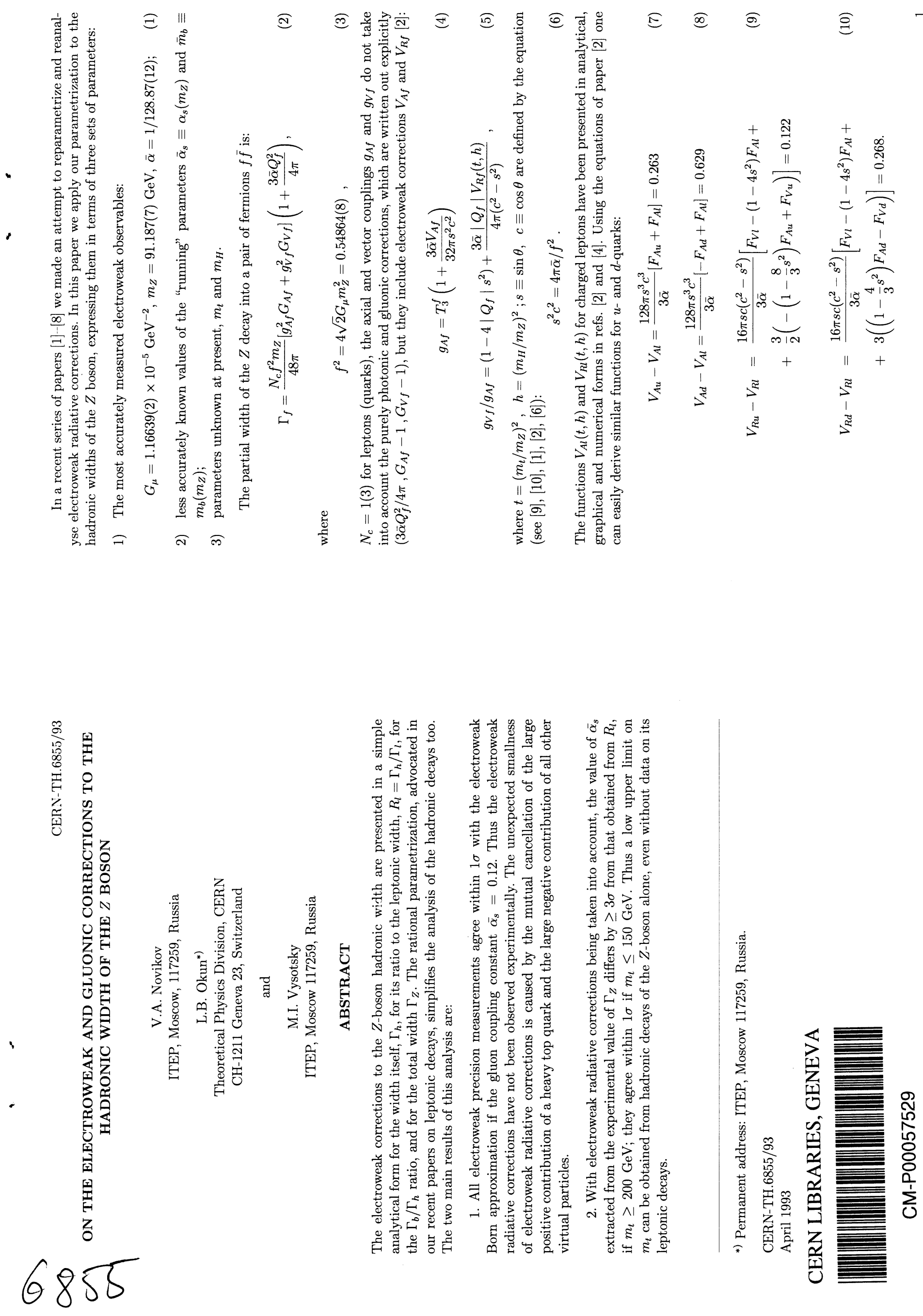

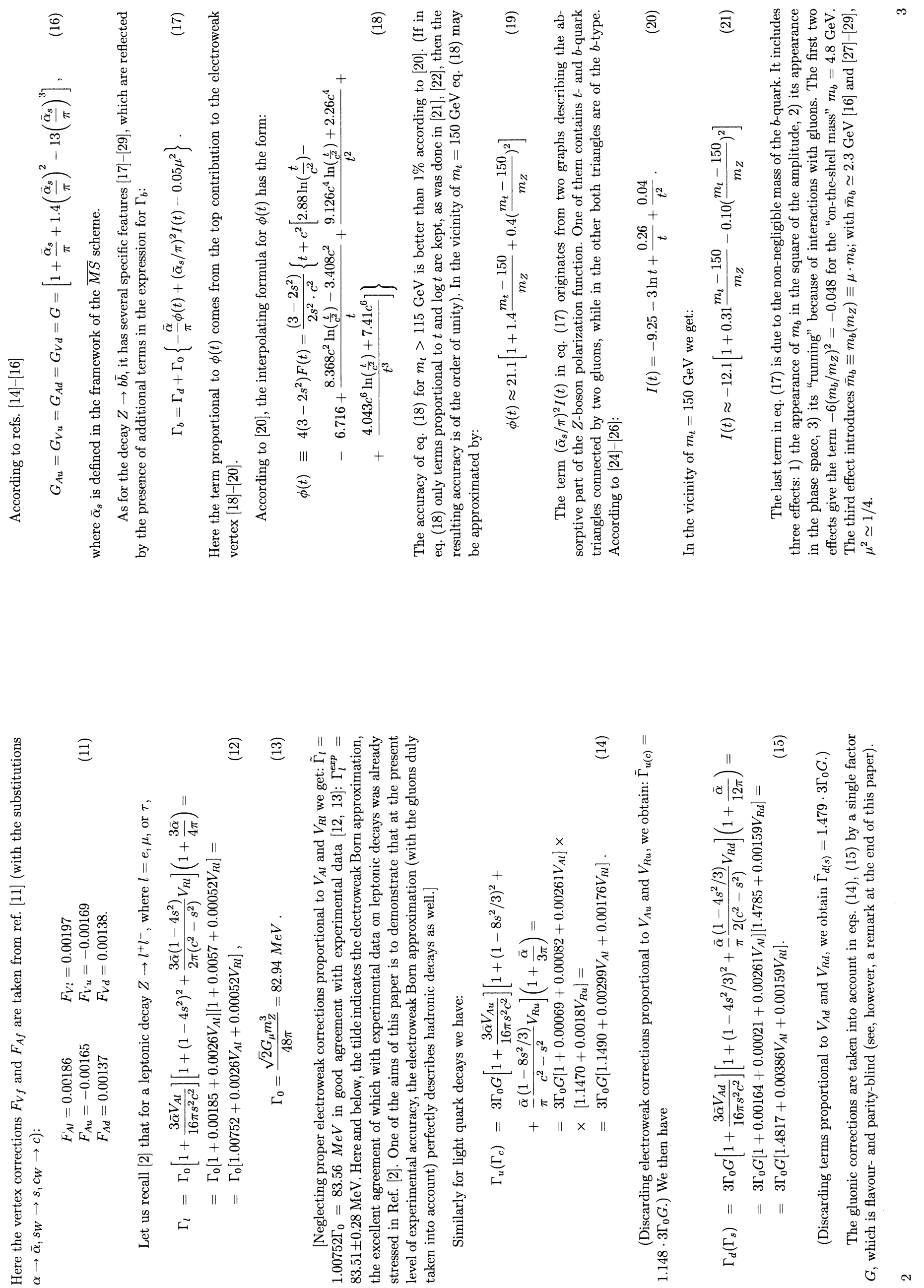

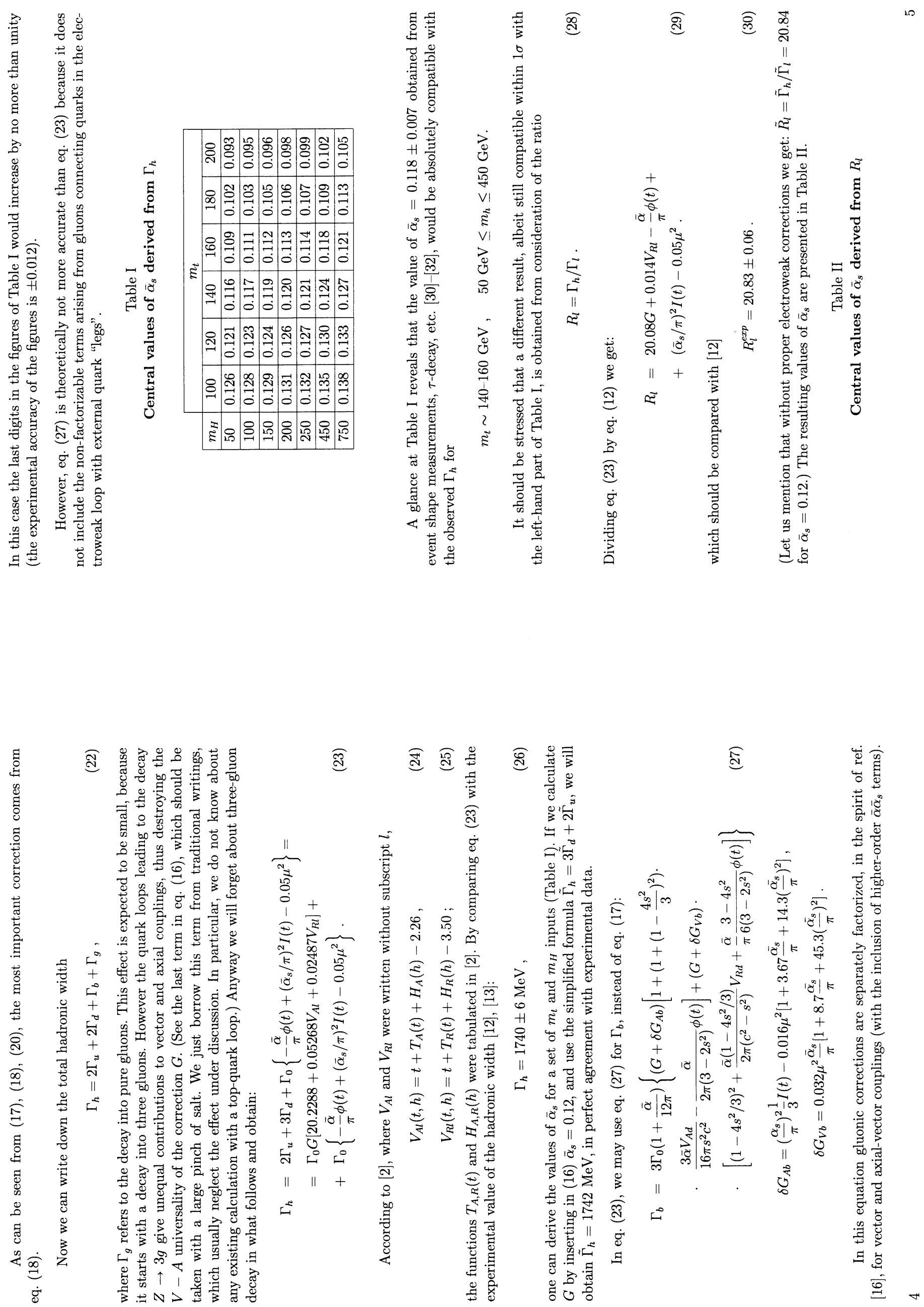

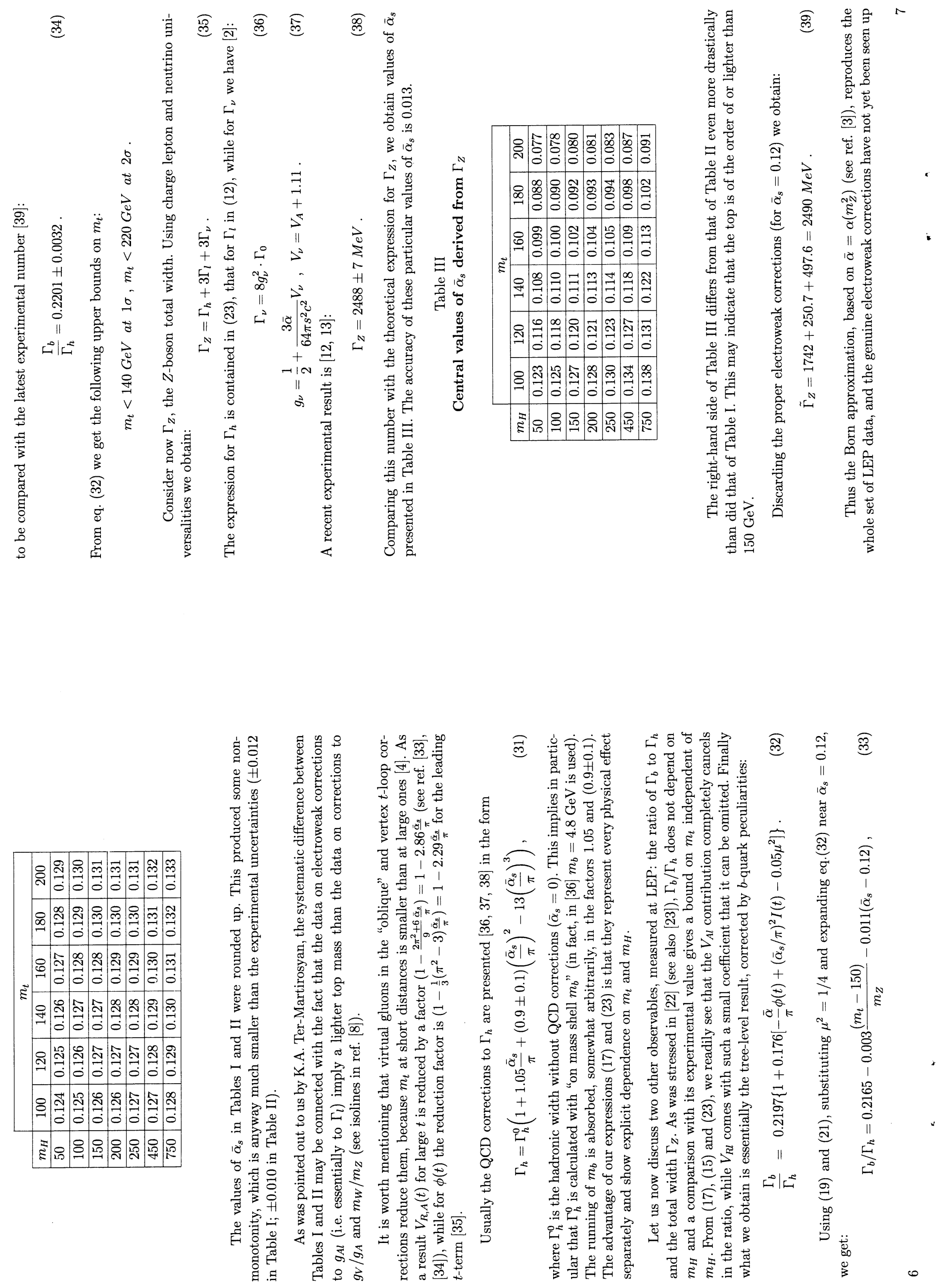


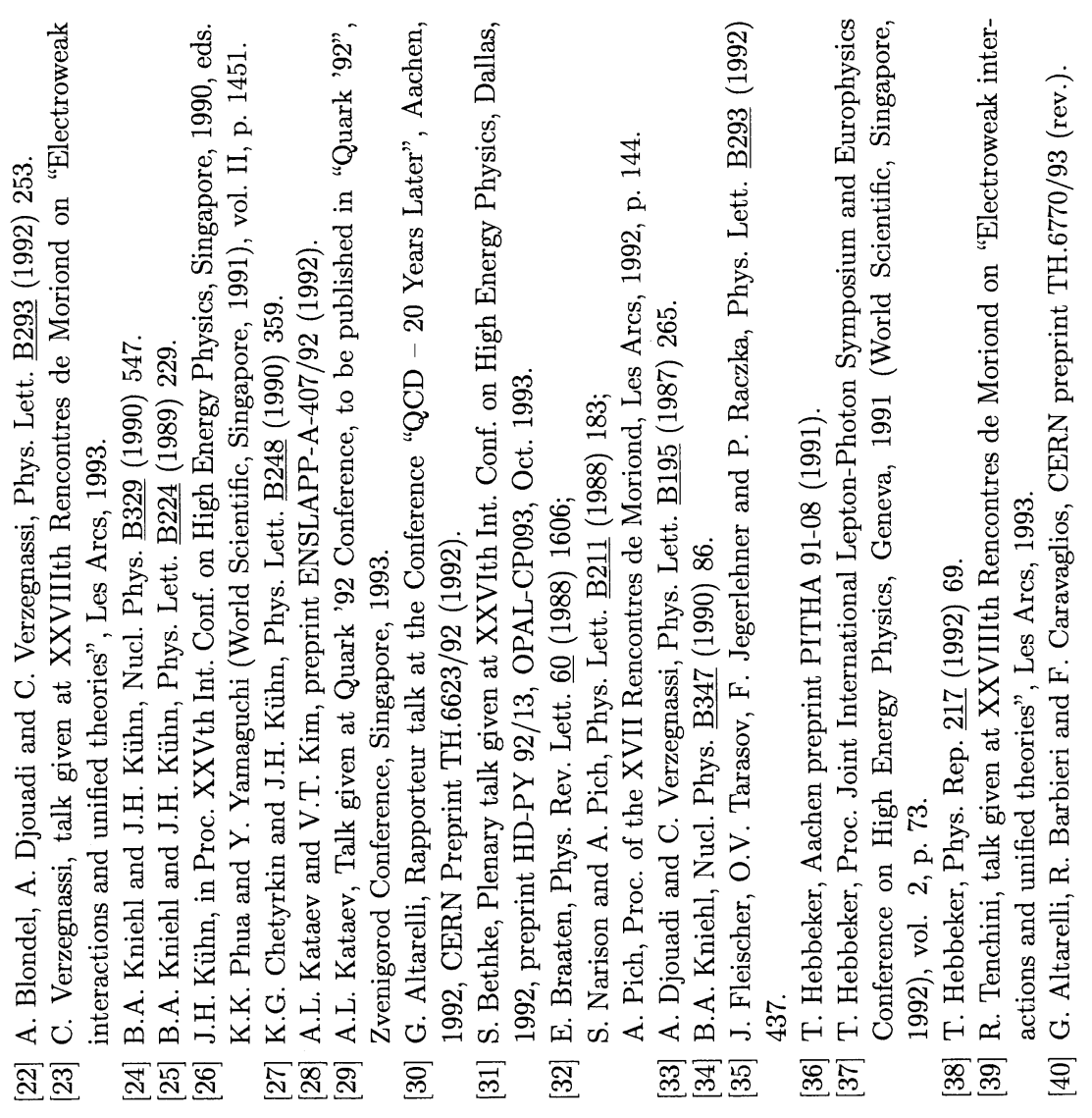

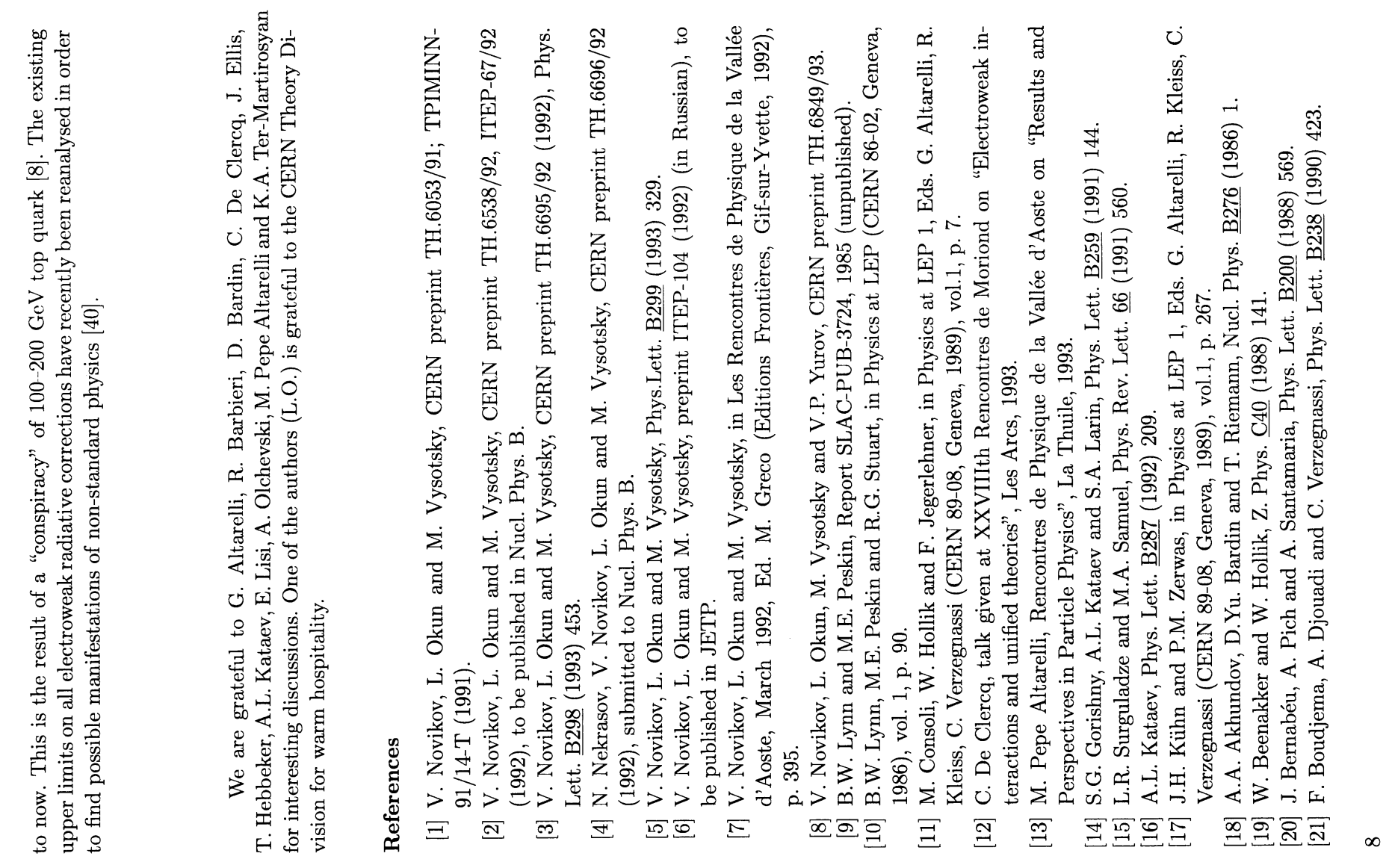

